\title{
Influence of Top Clearance Height in Airlift Reactor on the Aerobic Granular Formation
}

\author{
Andik Yulianto ${ }^{1, *}$, Yoanne Maretha Siswaya ${ }^{2}$, and Prayatni Soewondo ${ }^{2}$ \\ ${ }^{1}$ Posgraduate School, ITB, Jl. Ganesha 10 Bandung \\ ${ }^{2}$ Magister Program Environmental Engineering, ITB, Jl. Ganesha 10 Bandung \\ ${ }^{3}$ Department of Environmental Engineering, ITB, Jl. Ganesha 10 Bandung
}

\begin{abstract}
Conventional active sludge is the technology that is used commonly in wastewater treatment. However, this technology has the disadvantage, its relatively low settling speed causing a large land requirement. One technology that can be used to overcome this deficiency is aerobic granular. In this study aerobic granular is formed in a continuous flow system of airlift reactor with a 12 (twelve) hours hydraulic retention time. Aeration is carried out for 24 hours at a rate of 2 liters per minute (lpm). The height variation of top clearance (ht) is used to determine its effect on the aerobic granular formation. The ht variation used is $15 \mathrm{~cm}, 20 \mathrm{~cm}$, and $30 \mathrm{~cm}$. The height of top clearance at the airlift reactor affects the circulation and superficial gas velocity which then affect the hydrodynamic shear force. The larger the hydrodynamic shear force, the better the granular quality will be. The granular quality is determined based on physical characteristics including Sludge Volume Index (SVI), sludge density index (SDI), settling velocity, size, and aspect ratio. The result shows that the height of top clearance affects the granular quality that formed. However, the effect is not linear. The non-linearity of the relationship between the top clearance height and granular formation can be due to the sizeable superficial gas velocity and biomass washout. The ht variation that provides the best granular quality is achieved at 15 $\mathrm{cm}$, followed by $30 \mathrm{~cm}$, and finally $20 \mathrm{~cm}$. The ht variation of $15 \mathrm{~cm}$ reaches an optimum result with the value of SVI is $50 \mathrm{ml} / \mathrm{g}$, settling velocity $39,4 \mathrm{~m} / \mathrm{hour}$, SDI $2.02 \mathrm{~g} / \mathrm{ml}$, size $3.5 \mathrm{~mm}$, the aspect ratio of 0.86 , and organic removal efficiency reaches $87.2 \%$.
\end{abstract}

Keywords: wastewater, aerobic granular, airlift reactor, top clearance

\section{Introduction}

The growing of population leads to an increase in domestic activities and industrial activities. These activities produce waste products, which one of them is the liquid waste. This waste will pollute the environment if it is not processed first. Therefore, a processing technology is required so that liquid waste can be discharged into the water without polluting the environment. The technology which is commonly used in wastewater

\footnotetext{
Corresponding Author: yulianto.andik@gmail.com
} 
treatment is the conventional active sludge system [1]. However, this technology has a disadvantage. Its relatively low settling speed causing a large land requirement due to the longer time of hydraulic retention [2]. Therefore, a lot of research is conducted to optimize the process so that the problems in conventional technology can be improved.

One of the research is to modify the operational condition of wastewater treatment so that the granular sludge (bio granular) is formed. Bio granular is a collection of solid microbes which is formed by self-immobilization or aggregation of microorganisms involving biological, physical, and chemical phenomena [3]. The bio granular consists of microbe cells, inert particles, degraded particles, and polymer extracellular substances [4]. The settling rate of aerobic granular is high, therefore, it requires less area. Aerobic granular have a more extensive and compact surface, stronger microbial structures, better settling capability, higher biomass retention time, and higher capability in the process of organic loading rate (OLR) compared to conventional sludge processes [5].

Most aerobic granular are formed in a Sequencing Batch Reactor (SBR), thus the factors that are affecting aerobic granular formation are developed in SBR. However, several studies conduct aerobic granular development in the reactor with continuous flow system [6]. Also based on [6], the shearing stress that works in the solid phase in the continuous flow airlift fluidized bed reactor (CAFB) is one hundred times stronger than in the SBR at the same aeration force. This suggests that CAFB is highly efficient for granular formation. The airlift reactor can also form a stable and robust granular quickly and efficiently in nitrogen and organic clearance. The airlift reactor has a simple structure and can be operated efficiently, thus it provides a promising operation mode for the process of aerobic granular sludge formation. Another research shows that the aerobic bio granular formation process in the continuous reactor is more stable because of precipitation nucleus which is formed from iron and calcium [7]. However, based on [8], the formation of aerobic bio granular in the continuous reactor is not optimal when it is viewed from the settling rate and sludge volume index (SVI). One thing that can be done to improve the process of aerobic granular formation is to modify the reactor configuration. Therefore, in this study, the researchers use several height variations of top clearance $\left(h_{t}\right)$ to determine its effect on the aerobic granular formation.

The hypothesis to be proved in this study is that the lower the height of top clearance the better the aerobic bio granular formation process, which is seen from aspect ratio parameter, granular structure, granular size, settling rate, and SVI.

\section{Research Method}

\subsection{Wastewater composition}

In this research, it is used artificial wastewater with modified composition from [9]. The artificial wastes are made with a $\mathrm{C}: \mathrm{N}$ : $\mathrm{P}$ ratio of 100: 20: 1 wherein sodium acetate is used as a C-organic source, while $\mathrm{NH}_{4} \mathrm{Cl}$ and $\mathrm{K}_{2} \mathrm{HPO}_{4}$ as a source of nitrogen and phosphorus. Sodium acetate is used because of its simple structure and microorganisms quickly degrade it. The used composition of the artificial waste is shown in Table 1.

\subsection{Seeding and acclimatization}

Seeding is conducted to multiply the number of microorganisms which is going to be used in aerobic granular formation. The seeding sludge is taken from the Wastewater Treatment Plant of Jayakarta Hotel in Bandung. Seeding is carried out on a 40-liter container with the ratio of sludge and water is 3:1 (three to one). During the seeding, Total Suspended Solid 
(TSS) and Volatile Suspended Solid (VSS) are measured to determine the growth of microorganisms. Seeding is done until the desired VSS value is reached. In general, the minimum VSS which is used in the activated sludge process is $2,000 \mathrm{mg} / \mathrm{L}$.

Table 1. Wastewater composition

\begin{tabular}{|c|c|}
\hline Materials & Concentration \\
\hline $\mathrm{CH}_{3} \mathrm{COONa}$ & $4,962 \mathrm{mg} / \mathrm{L}$ \\
\hline $\mathrm{NH}_{4} \mathrm{Cl}$ & $717 \mathrm{mg} / \mathrm{L}$ \\
\hline $\mathrm{K}_{2} \mathrm{HPO}_{4}$ & $30.65 \mathrm{mg} / \mathrm{L}$ \\
\hline $\mathrm{KH}_{2} \mathrm{PO}_{4}$ & $22 \mathrm{mg} / \mathrm{L}$ \\
\hline $\mathrm{CaCl}_{2} \cdot \mathrm{H}_{2} \mathrm{O}$ & $60 \mathrm{mg} / \mathrm{L}$ \\
\hline $\mathrm{MgSO}_{4} \cdot 7 \mathrm{H}_{2} \mathrm{O}$ & $50 \mathrm{mg} / \mathrm{L}$ \\
\hline
\end{tabular}

After seeding, the acclimatization is conducted to adapt the microorganism with the waste that is going to be used. Comparison of sludge with the artificial waste is $3: 1$. At the acclimatization stage, TSS, VSS, and COD are measured. The acclimatization is done until the COD reduction approaches constancy. In both processes, the reactor is aerated for 24 hours and the $\mathrm{pH}$ is controlled in the range 6-8. When the $\mathrm{pH}$ is too acidic, it is added $\mathrm{Na}_{2} \mathrm{CO}_{3}$ until the $\mathrm{pH}$ is close to neutral.

\subsection{Reactor running}

In this study, it is used an airlift reactor with a continuous flow system as shown in Figure 1. The reactor configuration is adapted from the research of [6]. The reactor consists of the inner tube (draft tube) and outer column. The outer column diameter that is used is $10 \mathrm{~cm}$ with the height of $100 \mathrm{~cm}$, while the draft tube diameter is $5 \mathrm{~cm}$ with the top clearance height are varied, which are $15 \mathrm{~cm}, 20 \mathrm{~cm}$, and $30 \mathrm{~cm}$. The reactor is equipped with aeration diffuser placed at the bottom of the riser so that the water flow will move from the bottom up.

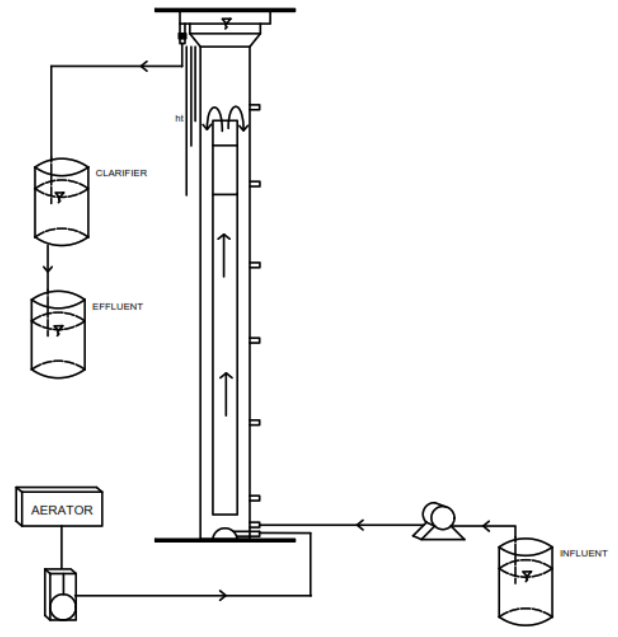

Fig. 1 Reactor configuration 
The continuous process is carried out by pumping artificial waste using a peristaltic pump. The Organic loading rate (OLR) that is used is $2.5 \mathrm{~kg} \mathrm{COD} / \mathrm{m}^{3} /$ day refers to [4], while the hydraulic retention time (HRT) used is 12 hours refers to [10]. During the study, the aeration is conducted for 24 hours with the aeration rate is 2 liters per minute. Aeration rate is adjusted by using flowmeter. The air is fed through the diffuser located at the bottom of the riser using an air pump with the capacity of $60 \mathrm{lpm}$.

To observe granular formation and development, the reactor is operated for three weeks. Based on [11], the formation of aerobic granular reaches a stable state after three weeks of reactor operation with constant development for the following week.

\subsection{The parameter test method}

Samples are taken by using the grab sampling method. The measured parameters, sampling periods, and measurement methods are shown in Table 2. The measurement method used refers to the Standard Methods for the Examination of Water and Wastewater (SMEWW). The method of settling velocity measurement, aspect ratio, size, and granular structure is not present in the SMEWW, thus the parameters are measured as follows.

Settling velocity is measured by separating the granular which is already formed from the ordinary active sludge floc. Afterward, the granular is put into a $100 \mathrm{~mL}$ measuring cylinder to observe its settling time. The measurement of granular size is performed by measuring the diameters of some granular. The granular is placed on a petri dish then is documented by using a camera. Then, the photos are opened in AutoCAD and measured the diameters for 10 granule samples. This method refers to the research conducted by [12]. The initial step of measuring aspect ratio is the same as the measurement of granular size. On each granule, the researchers draw four lines to determine the longest distance and the shortest distance from one granule. The aspect ratio value is determined by comparing the smallest size with the largest size of a granular. The granular structure is known by using the gram staining method and the observation using a compound light microscope.

Table 2 Measurement Method and intensity

\begin{tabular}{|c|c|c|}
\hline Parameter & Measurement Intensity & Method \\
\hline $\mathrm{pH}$ & \multirow[t]{10}{*}{ 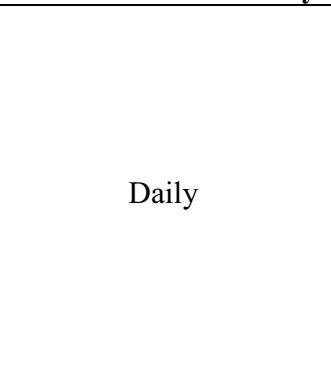 } & SMEWW-4500-H \\
\hline DO & & SMEWW-4500-O \\
\hline Temperature & & SMEWW-2550 \\
\hline SVI & & SMEWW-2710-D \\
\hline SDI & & \\
\hline TSS & & SMEWW-2540-D \\
\hline VSS & & SMEWW-2540-D \\
\hline Settling velocity & & \\
\hline Size & & \\
\hline Aspect ratio & & \\
\hline Structure & Once a week & \\
\hline COD & Daily & SMEWW-5220-C \\
\hline
\end{tabular}

*The methods are not present in the SMEWW

\section{Result and Discussion}

Its physical characteristics determine the aerobic granular quality. The granular physical characteristics which observed in the study are SVI, sludge density index (SDI), settling velocity, granular size, aspect ratio, and granular structure. The results show that top 
clearance height $\left(h_{t}\right)$ affecting granular quality that formed. The effect is due to the difference of circulating speed in the reactor. The higher the $h_{t}$, the slower the circulation speed. The speed of circulation will then affect the shearing stress which is a factor affecting the granular quality. However, the effect is not linear. The non-linear relationship between the top clearance height and granular formation can be due to superficial gas velocity [13] and biomass washout. The result data are shown in Figure 2 to Figure 6.

SVI is used to measure Mixed Liquor Suspended Solid (MLSS) capability in routine and design operations [14]. Comparison of SVI value is shown in Figure 2. According to [15], activated sludge with good settling capability has an SVI value of $90-120 \mathrm{ml} / \mathrm{g}$, whereas the SVI value for granular is in the range $50-85 \mathrm{ml} / \mathrm{g}$ [16]. Based on Figure 2 it is found that the variation that gives better SVI value is the variation with the lowest $h_{t}$ value, that is $15 \mathrm{~cm}$. The SVI value of this variation is in the granular SVI range. The $20 \mathrm{~cm} \mathrm{~h}_{\mathrm{t}}$ variation gives the highest SVI value, it indicates that this variation gives the least SVI value. When compared to granular formation on SBR, the SVI value of SBR continues to decrease during the reactor operation time [17]. This shows that SBR gives the better result in SVI parameter.

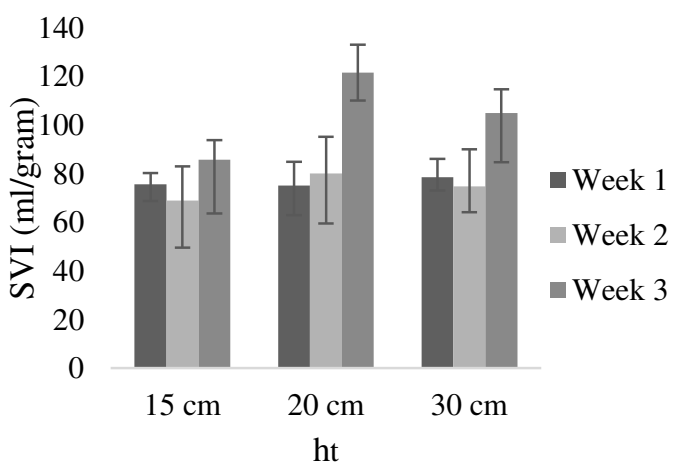

Fig. 2 Comparison of SVI values

SDI is related to the aerobic granular density level that formed which then affects the granular settling velocity. The denser and more cohesive the granular is formed, the higher the measured density value. According to [18], aerobic granular has a density of $3.22 \mathrm{~g} / \mathrm{mL}$. SDI observation results are shown in Figure 3. The best SDI was achieved when $h_{t}$ is 15 $\mathrm{cm}$, i.e with an average SDI is $1.34 \mathrm{~g} / \mathrm{ml}$. This value has not met the ideal granular SDI value, but it has met the optimum criteria of active sludge which has a range of 1.0-2.5 $\mathrm{g} / \mathrm{mL}[19]$. This indicates that the system is still dominated by activated sludge floc.

The settling velocity is one of the critical parameters to determine the quality of aerobic granular. The higher the settling velocity, the better the result of aerobic granular quality. According to [20], aerobic granular settling velocity reaches $30-70 \mathrm{~m} / \mathrm{hr}$. The comparison of the settling velocity is shown in Figure 4. It is known that the average value of settling velocity for $h_{t}$ variation of $15 \mathrm{~cm}, 20 \mathrm{~cm}$, and $30 \mathrm{~cm}$ respectively are $28.6 \mathrm{~m} / \mathrm{h} ; 21.4 \mathrm{~m} / \mathrm{h}$; and $20.63 \mathrm{~m} / \mathrm{hr}$. This shows that the best settling velocity is achieved at $15 \mathrm{~cm} \mathrm{~h}_{\mathrm{t}}$ variation. The lower the top clearance height, the higher the circulation rate which caused the high shear force of hydrodynamics. This affects the granular density formed. The high value of settling velocity indicates the solid granular structure.

The granular size is one of the parameters associated with morphology and settling [3]. According to [21] the optimum granular diameter for each active microorganism to perform its respective roles is smaller than $3.5 \mathrm{~mm}$. Comparison of granular size is shown in Figure 5. It is known that the largest granular size is successively achieved at variations of $15 \mathrm{~cm}, 30 \mathrm{~cm}$, and $20 \mathrm{~cm}$, with an average size of $2.3 \mathrm{~mm} ; 1.9 \mathrm{~mm}$; and $2.2 \mathrm{~mm}$. 


\section{5}

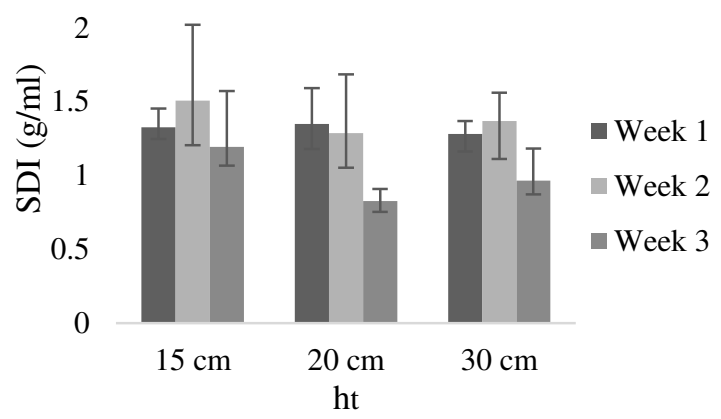

Fig. 3 Comparison of SDI values

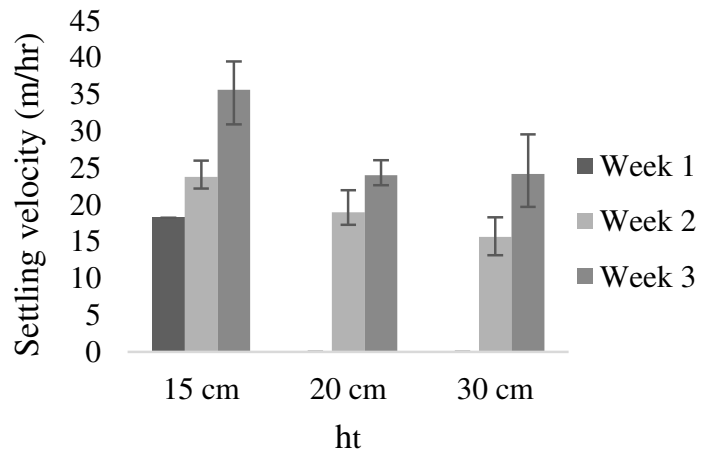

Fig. 4 Comparison of settling velocity values

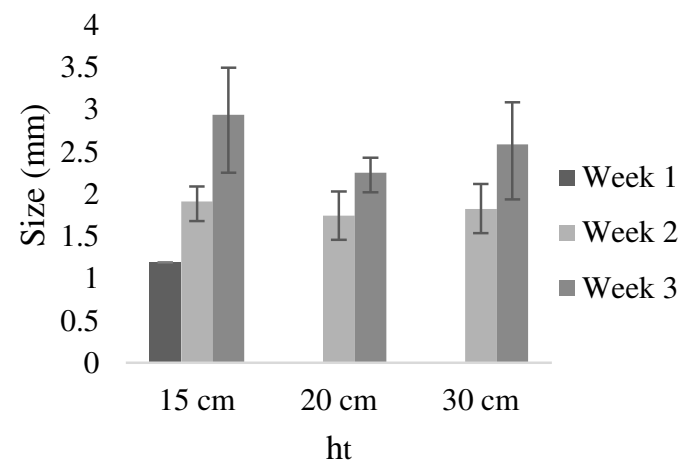

Fig. 5 Comparison of granular size

This indicates that the granular size of all variations meets the ideal granular size. The influence of hydrodynamic shear forces on granular formation is not linear. Other factors may affect the development of granular size, one of them is biomass washout. At $a h_{t}$ variation of $30 \mathrm{~cm}$, the probability of biomass washout occurrence is less than other variations. This causes the granular to become more stable and not susceptible to rupture due to the recirculation of the sludge. 
Aspect ratio is one factor of aerobic granular morphology. The aspect ratio value is measured to determine the level of granular roundness that is formed. Aspect ratio is calculated by dividing the shortest diameter and longest diameter. If the aspect ratio value of the granular close to one then granular has a round shape. Whereas, if the aspect ratio is close to zero then the granular shape almost resembles a line. According to [18], a proper aspect ratio value for granular which is formed using acetate substrate is 0.73 .

Comparison of aspect ratio is shown in Figure 6. Based on Figure 6 it is known that the aspect ratio for each variation has almost the same value, with an average value of 0.76 . This indicates that the formed granular has an ideal aspect ratio value with the shape close to round. The high aspect ratio value indicates the hydrodynamic force in the reactor has been high enough to form an ideal granular.

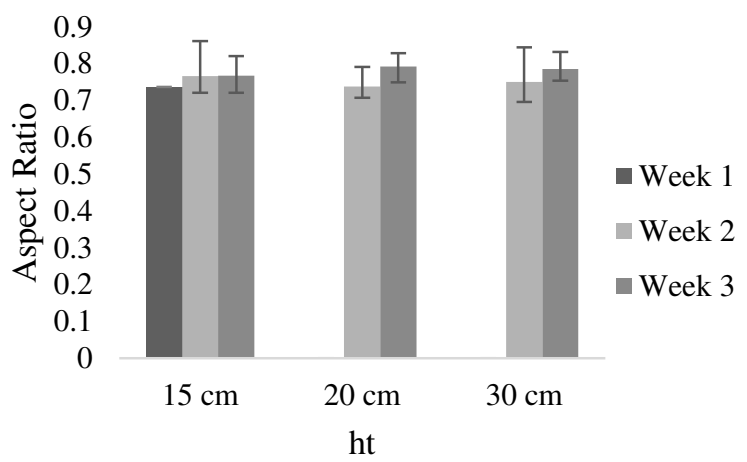

Fig. 6 Comparison of aspect ratio

Observation of granular structure is done by Gram staining method. The results of the granular structure observation are shown in Table 3. At $h_{t}$ variation of $15 \mathrm{~cm}$, aerobic granular has been formed at the end of the first week, whereas in the $h_{t}$ variation of $20 \mathrm{~cm}$ and $30 \mathrm{~cm}$, aerobic granular has not been formed, there are only very small flocs. Based on the picture, the granular structure on $\mathrm{h}_{\mathrm{t}} 15 \mathrm{~cm}$ has not been cohesive since there are still some cavities. This indicates that granular has not progressed steadily. The shape of the formed granular approaches round but still irregular.

In the second week of the $15 \mathrm{~cm} \mathrm{~h}_{\mathrm{t}}$ variation, the formed granular has begun to dense, there is no cavity on it. However, the form is still not round. Granular begins to form and reaches a larger size by the end of the second week for the $20 \mathrm{~cm} \mathrm{~h}_{\mathrm{t}}$ variation. The observed granular structure has almost an oval shape and has a quite large cavity. For the $30 \mathrm{~cm} \mathrm{~h}_{\mathrm{t}}$ variation, the observed granular structure has an oval shape with irregular sides and there are several cavities in the smaller size. This shows that the formed granular is quite optimal.

In the third week, it is observed that granular in the variations of $15 \mathrm{~cm}$ and $30 \mathrm{~cm}$ have more compact structure, whereas, in the $20 \mathrm{~cm}$ variation, the granular has a more irregular structure. This shows that in the variation of $20 \mathrm{~cm}$, the granular formed start to experience lysis.

COD removal measurement is performed to determine the aerobic granular ability in excluding organic compounds. The comparison of COD removal efficiency for the three variations is shown in Figure 7. Based on the measurement results, the greatest elimination efficiency is the variation of ht $20 \mathrm{~cm}$ that is $81,6 \%$, followed by at $15 \mathrm{~cm}$ as much $80,8 \%$, and at $30 \mathrm{~cm}$ is $80.5 \%$. This is influenced by the amount of biomass in the reactor. The more biomass in the system, the higher the COD removal efficiency. According to [18], the efficiency of organic removal in aerobic granular with acetate substrate can achieve $98 \%$ 
efficiency. This study does not achieve this efficiency due to the nonoptimal granular formation.

Table 3 Granular structure development
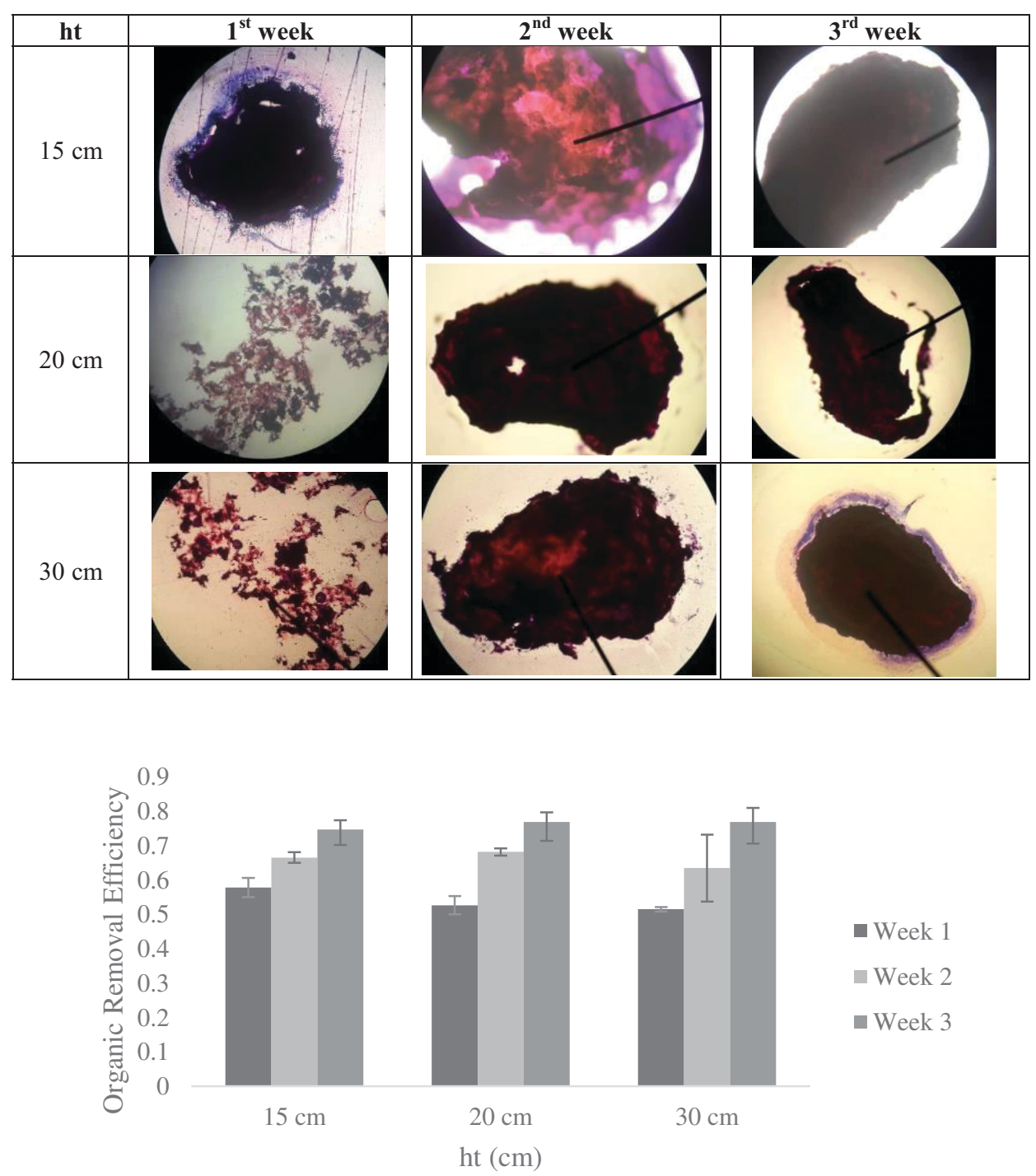

Fig. 7 Comparison of COD removal

\section{Conclusion}

Based on the results of the research, it is known that the top clearance height affects the formation of aerobic granular. However, the relationship between top clearance and granular characteristics is not linear. This is due in no small amount of superficial gas velocity that is used. In addition, there is an influence of biomass washout that is occurred. 
A variation that provides the best granular quality is achieved at $h_{t} 15 \mathrm{~cm}$. In this variation, the granular has an optimum value of SVI that is $50 \mathrm{mg} / 1$, SDI $2.02 \mathrm{~g} / \mathrm{mL}$, settling velocity $39.4 \mathrm{~m} / \mathrm{h}$, size $3.5 \mathrm{~mm}$, and aspect ratio 0.86 .

\section{Acknowledgements}

This research was funded from Penelitian Disertasi Doktor (PDD) Research scheme. The authors would like to thank Kemenristekdikti for providing funding, and the Direktorat penelitian dan Pengabdian Masyarakat (DPPM) Universitas Islam Indonesia which has facilitated this research scheme.

\section{References}

1. Morales, N., Figueroa, M., Corral, M. A., Campos, J.L., and Mendez, R. (2012): Aerobic granular-type biomass development in a continuous stirred tank reactor, Separation and Purification Tech., 89, 199 - 205.

2. Iaconi, D.C., Ramadori, R., Lopez, A., Passino, R. (2007): Aerobic granular sludge systems: the new generation of wastewater treatment technologies, Industrial \& Engineering Chemistry Research, 46, 6661 - 6665.

3. Liu, Y. and Fang H.H.P. (2003): Influence of extracellular polymeric substances (eps) on flocculation settling and dewatering of activated sludge, Crit Rev Environ Sci Technol, 33, $237-273$.

4. Bachtiar, W and Handajani M. (2013): Penentuan kondisi optimum untuk pembentukan biogranular aerob dengan sequencing batch reactor, Tugas Akhir, Institut Teknologi Bandung.

5. Chen, Y., Lin, C., Chen, H., Fu, S., and Zhan, H. (2009): Cultivation of biogranules in a continuous flow reactor at low dissolved oxygen, Water Air Soil Pollution, 9, 213 221.

6. Zhou, D., Liu, M., Wang, J., Dong, S., Cui, N., and Gao, L. (2012): Granulation of activated sludge in a continuous flow airlift reactor by a strong drag force, Biotechnology and Bioprocess Engineering, 18, 289 - 299.

7. Juang, Y.C., S.S. Adav, D.J. Lee, and J.H. Tay (2010): Stable aerobic granules for continuous-flow reactors: Precipitating calcium and iron salts in granular interiors, Bioresource Technology, 101, 8051 - 8057.

8. Yulianto, A., Soewondo, P., Handajani, M., and Ariesyady, H.D. (2017): Preliminary study on aerobic granular biomass formation with aerobic continuous flow reactor, American Institute of Physics Conference Proceedings 1823, 020113.

9. Koh, K.Y., Kueh, K.H., Loh, K.T., Leong, H.J., Chua, A.S.M., and Hashim, M.A. (2009): Effect of seeding sludge type and hydrodynamic shear force on the aerobic sludge granulation in sequencing batch airlift reactors, Asia-Pacific Journal of Chemical Engineering, 4, 826 - 831.

10. Zakiyya, N. and Soewondo, P. (2016): Penyisihan senyawa organik and nitrogen menggunakan biogranular aerob pada airlift reaktor, Tesis Magister, Institut Teknologi Bandung.

11. Yang, S.F., Tay, J.H., and Liu, Y. (2005): Effect of substrate nitrogen/chemical oxygen demand ration on the formation of aerobic granule, Journal of Environmental Engineering, 131, $86-92$. 
12. Lee, D. J., Chen, Y. Y., Show, K. Y., Whiteley, C. G., and Tay, J. H. (2010): Advances in aerobic granule formation and granule stability in the course of storage and reactor operation, Biotechnology Advances, 28, 919 - 934.

13. Blazej, M., Kisa, M., and Markos, J. (2004): Scale influence on the hydrodynamics of an internal loop airlift reactor, Chem.Eng Process, 43, 1519 - 1527.

14. Jin, B., Wilen, B.M., and Lant, P. (2003): A comprehensive insight into floc characteristics and their impact on compressibility and settleability of activated sludge, Chem.Eng.J, 95, 221 - 234.

15. Richard, M. (2003): Activated sludge microbiology problems and their control. Annual USEPA National Operator Trainers Conference.

16. Tay, J. H., Liu Q. S., and Liu, Y. (2001): The effects of shear force on the formation, structure and metabolism of aerobic granules, Applied Microbiology and Biotechnology, 57, $227-233$.

17. Putri, K. K. and Soewondo, P. (2016): Pengaruh C/N pada pembetukan biomassa granular aerobic dalam Sequencing Batch Reaktor, Tugas Akhir, Institut Teknologi Bandung.

18. Tay, J.H., Liu, Q.S., and Liu, Y. (2002): Characteristics of aerobic granules grown on glucose and acetate in sequential aerobic sludge blanket reactors, Environmental Technology, 23, 931 - 936.

19. Runion, R. (2010): Activated sludge treatment process-what volume and density limit are ideal, Ezine Articles.

20. Liu, Y. and Tay, J. (2004): State of the art of biogranulation technology for wastewater treatment, Biotechnology Advances, 23, 533 - 563.

21. Liu, Y. and Tay, J.H. (2002). The essential role of hydrodynamic shear force in the formation of biofilm and granular sludge, Water Res, 36, 1653 - 1665. 